\title{
Transforming Young Minds socially through, a course Social Innovation with a Human Centred Design Approach at freshman level of Engineering.
}

\author{
Jayanti Shinge ${ }^{1}$, Sanjay V Kotabagi ${ }^{2}$, Geeta $\mathbf{M}^{3}$, Christina Rebello ${ }^{4}$, Sujatha $\mathrm{N} \mathrm{M}^{5}$, Anusha $\mathrm{K}^{6}$ \\ ${ }^{1}$ Asst Professor, Department of Humanities and Social Sciences, KLE Technological University, Hubli, Karnataka. \\ ${ }^{2}$ HOD, Department of Humanities and Social Sciences, KLE Technological University, Hubli, Karnataka. \\ ${ }^{3}$ Asst Professor, Department of Humanities and Social Sciences, KLE Technological University, Hubli, Karnataka. \\ ${ }^{4}$ Lecturer, SJMV Sangha's Business Administration College for Women, Hubli, Karnataka. \\ ${ }^{5}$ Asst Professor, Department of Humanities and Social Sciences, KLE Technological University, Hubli, Karnataka. \\ ${ }^{6}$ Asst Professor, Department of Humanities and Social Sciences, KLE Technological University, Hubli, Karnataka. \\ 1jayanti_s@kletech.ac.in \\ ${ }^{2}$ sanjay_kotabagi@kletech.ac.in \\ ${ }^{3}$ geeta@kletech.ac.in \\ ${ }^{4}$ christinarebello25@gmail.com \\ ${ }^{5}$ sujatha_nm@kletech.ac.in \\ 6anushak@kletech.ac.in
}

\begin{abstract}
:
We at KLE Tech strongly believe in the philosophy of sensitizing young minds socially and establishing a social connect with the society they live in. Social Innovation is a uniquely designed two-credit course for freshman students of engineering; which catalyses this need through experiential learning and community engagement. The course allows the students to get engaged with the society, stake-holders to find out the prevailing social issues which need their immediate intervention. We have adopted the Human Centred Design Approach which helps the students' delayer the social issues systematically and provide feasible and sustainable solutions.
\end{abstract}

Design thinking approach helps students to think over the creative process that engages them in opportunities to experiment, create and prototype models, collect feedback, and redesign the solution keeping end-user in the mind. The course is delivered by a heterogeneous team of experts. Students' learning is enhanced through field visits, presentations and peer reviews. Student teams engage in multiple community studies to identify a social issue. The social issue is better understood through stakeholder interactions and brainstormed among the teams to look for multiple solutions. The best-suited solution is implemented and its effectiveness is studied. Student's performance is evaluated through classroom presentations and projects.

This course has helped in inducing competencies such as social responsibility, problem-solving skills, observation skills, critical thinking ability, communication skills, teamwork and lifelong learning.

Keywords:
Social Innovation, freshman, Engineering, Human Centred Design approach, Social Issue, Solutions.

\section{Introduction}

A course on 'Social Innovation' has been conceptualized and offered to the freshman students of undergraduate engineering. The fundamental objective of this course is to facilitate student's capacity to use problem-solving skills to address social issues through innovative solutions and to transform students perspective on the world around them by enabling them to identify areas ripe for innovation. This course adopts the design thinking approach which helps students adopt a creative process that engages a person in opportunities to experiment, create and prototype models, gather feedback, and redesign.

Human-centred design thinking approach, adjuncts to create products, services, and awareness that improves the lives of stakeholders living in different communities.

Engage is the first phase of design thinking where students are engaged in multiple community visits to understand the lives of the people and their problems by observing and interacting with them.

The second phase is Inspiration; students indulge themselves with focused discussions or one on one interview with stakeholders and experts for the deep understanding of the social issue.

Ideation phase has two different verticals, synthesis, and prototyping where students brainstorm among their teammates and with the facilitator in identifying multiple solutions for the identified social issue.

The fourth phase is implementation, students try to implement the best-prioritized solution for a social issue and 
build an innovative prototype/service to serve the community.

Reflect is the last phase where the feedback for the service and on the prototype developed is been taken from the community stakeholders to improvise the product/service.

\section{The Human-centred design approach}

Human-centred design is a methodology for devising successful design solutions. According to this methodology, designers focus on end-users from the very beginning of product creation and have users testing each iteration of a product. As a result, end-users get a product that satisfies their needs.

The human-centred design does not simply force you to consider the needs and wants of product users first. The question is how you can satisfy those needs in both functional and emotionally meaningful ways. There are three general principles of human-centred design:

- Collaboration. Great minds create great ideas when they work together.

- Empathy. You can't create a product for people if you don't deeply understand their motivations.

- Experimentation. It's only through conversations, experiments (checking hypotheses), and learning that a great product is born.

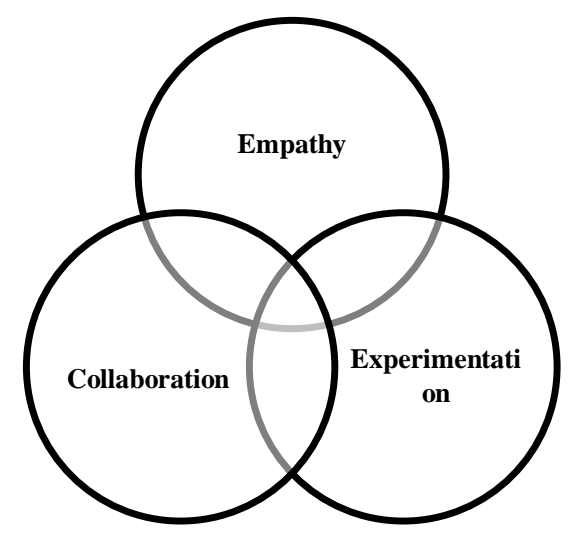

(Fig 1: Human-centred Design Approach)

Process of Human Centred Design Approach:

The Design Thinking process is iterative, flexible and focused on collaboration between designers and users, with an emphasis on bringing ideas to life based on how real users think, feel and behave.

Design Thinking tackles complex problems by:

1. Empathising: Understanding the human needs involved.
2. Defining: Re-framing and defining the problem in human-centric ways.

3. Ideating: Creating many ideas in ideation sessions.

4. Prototyping: Adopting a hands-on approach in prototyping.

5. Testing: Developing a prototype/solution to the problem.

\section{Unique Process of Social Innovation}

The process of Social Innovation is uniquely designed which creates a platform for students to look at the social problem with a wide lens. The integration of social innovation with human centric design approach in engineering education helps in,

1. Building innovation capacity in students by exposing them to the real life social challenges prevailing in the society.

2. Preparing students for recognizing the social challenges with the mindsets and methods of human-centered design so that the students can be more intentional about facing and solving current social challenges with their ability of critical thinking and continuous stake holder engagement.

3. Social Innovation framework with the human centric design challenge assists students in giving sociotechnological solutions to the societal problems. It also helps in identifying the patterns and opportunities for concept development.

Let us now explore the process in detail.

\section{Social Innovation Process: Designed with HCD}




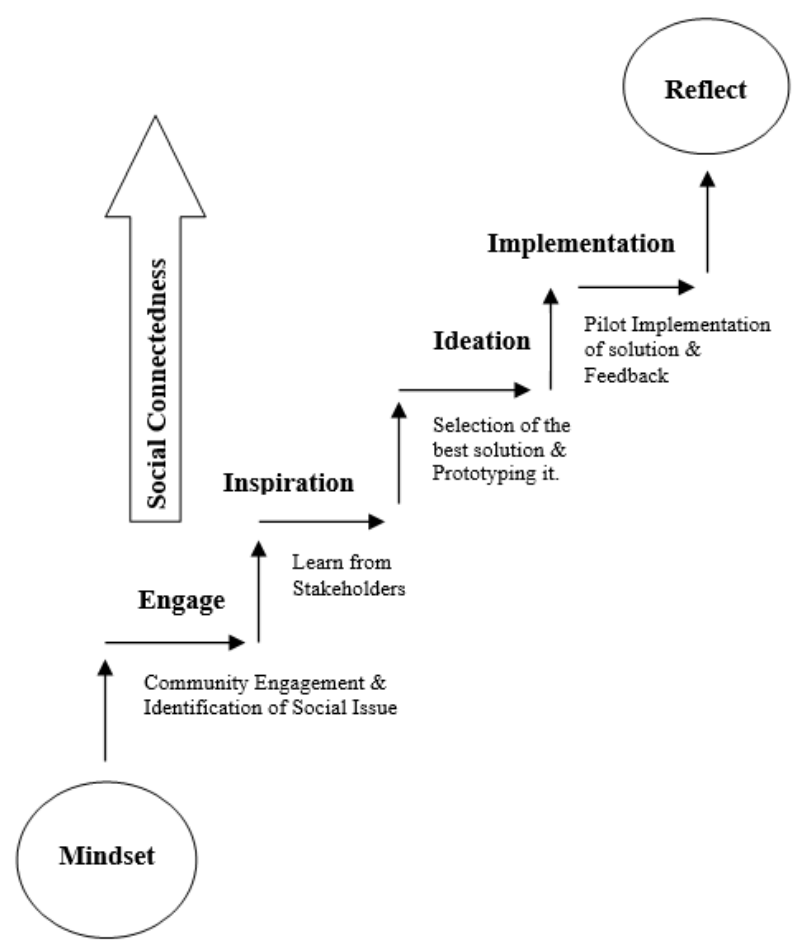

(Fig 2: Social Innovation Process)

\section{Mindset:}

\section{Empathy}

Students are oriented on what is the difference between sympathy and empathy.

- Sympathy is feeling compassion, sorrow, or pity for the hardships that another person encounters.

- Empathy is putting you in the shoes of another.

Example:

1. I see a beggar begging on the road, Sympathy: I would feel bad for that person and might also help him.

\section{Creative Confidence}

Creative confidence is the quality that human-centred designers rely on when it comes to making leaps, trusting their intuition, and chasing solutions that they haven't figured out yet. It is the belief that you can and will come up with creative solutions to big problems and the confidence that all it takes is rolling up sleeves and diving in.

\section{Make It}

Make it is the quality that human-centred designers rely on when it comes to building our ideas so that we can test them, and because making something reveals opportunities and complexities that we'd never have guessed were there. We make using anything at our disposal, from cardboard and scissors to sophisticated digital tools.

\section{Learn from Failure}

It is an inherent part of the human-centred design because we rarely get it right on our first try. Getting it right on the first try isn't the point at all. The point is to put something out into the world and then use it to keep learning, keep asking, and keep testing. We get something right after getting it wrong in the first place.

\section{Embrace Ambiguity}

It starts from the place of not knowing the answer to the problem they are looking to solve. It frees us to pursue an answer that we can't imagine which puts us on the path to routine innovation and lasting impact.

\section{Optimism}

We believe that design is inherently optimistic. To take on a big challenge, especially one as large and intractable as poverty, we have to believe that progress is even an option. If we wouldn't even try. Optimism is the embrace of possibility, the idea that even if we don't know the answer, that it's out there and that we can find it.

\section{Iterate, Iterate, Iterate}

We adopt an iterative approach to solving problems because it makes feedback from the people we are designing for a critical part of how a solution evolves. But continually iterating, refining, and improving our work, we put ourselves in a place where we will have more ideas, try a variety of approaches, unlock our creativity, and arrive more quickly at successful solutions.

\section{Engage Phase:}

During the engage phase students are exposed to the community engagement. The students go into the unknown community to observe the community and its people. No interaction happens during the first community engagement. Students are oriented on the mindset of empathy before they go into the community.

After the orientation students are sent out in the community to capture social conditions which they find unusual keeping their empathetic vision on. For example,

- If a kid in class 4 is selling vegetables in the vegetable market in the evening.

- If a group of school going kids are playing cricket in the ground on a working day.

- If a youth of the age group 20 -25 years are whiling away the time playing cards under the banyan tree at $12 \mathrm{pm}$.

With the follow-up community engagements, the students start interacting with the people. Students are not usually 
given examples on what to observe in the form of social issues, but before they step into the community visit they would know the following:

- Who are Engineers?

- What is their role in society?

- What is Society?

- What are Social Issues?

- How Social Issues are different from Personal Issues?

- What is Social Innovation?

- What are the observation skills and the community visit?

- What are the unusual social conditions?

\section{Inspiration Phase:}

The inspiration phase takes the students close to the social condition as they try to delayer them through the series of community engagements. They start recognizing the stakeholders, the primary stakeholders who are the direct sufferer the secondary stakeholders who are directly or indirectly affected and the tertiary who are experts who can give the students varied inputs to resolve the issue based on their experience. Students arrange for one on one interview with all the stakeholders for the deeper understanding of the social issue. Their continuous community engagement helps them answer the following questions.

- Identify the different categories of stakeholders like,

- Primary Stakeholders ( sufferers)

- Secondary stakeholders ( indirectly related to the social issue)

- Experts ( who can give the students varied inputs to resolve the issue based on their experience)

- How to justify the social condition as a social issue in the form of literature review and statistics to quantify, verify and justify the gravity of the problem?

- What is the gravity of the issue?

- What is the plight of the sufferer?

- How to develop a detailed interview guide for the different categories of stakeholder?

- What an interview is?

- How to start a conversation with the unknown stakeholders and seek their help in delayer the social condition?

- How to capture the learning from the stakeholders?

- How to recognize and find out the right group of experts to learn from, on the various ways to resolve the issue?

\section{Ideation Phase (Synthesis):}

The ideation phase students try to learn and make sense of the vast amount of data in the form of learning to identify opportunities for design in the following flow,

1. Learnings captured are streamlined and the common ones bucketed.

2. Themes are written for these bucketed common insights.

3. The prominent insight is then converted to a "How might question" to check and answer the feasibility in finding solutions to the prominent insight. This phase helps students generate lots of ideas, some of which are kept and some of which are discarded.

4. The "How might we" questions are then pasted onto a big whiteboard and students start writing solutions onto colourful post sticks onto the board to these questions as a part of "Story Board Activity"

5. Once students are done with pasting multiple solutions answering the "how might questions", they brainstorm amongst themselves and with the faculty to pick the first best, the second best and the third best.

6. The solutions picked up are then individually rated by the group members on the following given questions separately on the scale of 5 ,

1. Instinctively, how excited are you about this idea?

2. How innovative and different from what's out there does this idea feel?

3. How practical do you think this idea is?

4. Does implementing it seem realistic?

7. One solution is thus finalized for implementation.

\section{Ideation Phase (Prototype):}

This phase enables the students to design a prototype or sketch the plan for the implementation of the solution finalized for resolving the social issue.

Students concentrate on,

- Determine what to prototype.

- Make the prototype.

- Test the prototype.

\section{Implementation:}

This phase students implement the solution at the community for the social issue they identified. After one week of the implementation, students go back into the community to collect the feedback on the solution asking if the solution has brought in any change their lives and has resolved their problems.

Sample Projects: 
The following sample projects highlight how the freshman students of engineering got socially connected to the people in need and provided feasible and sustainable solutions to the social issue they found during their community engagements.

\section{Connecting Orphanages with Old Age Homes: A Triumph over Loneliness.}

A group of five students from "A" division namely, Shashank Halemani, Praveen Kotur, Sheetal L, Ronit Kumar Pujar and Abhishek N Wankhede as a part of their Social innovation Project went to a community visit during their initial classes.

Their first community visit required them to go for enlisting their observations on whatever was not normal according to them into the society. These pack of students mainly from CS and EC made their visit to an Orphanage named ABC. During their, after visit classroom presentation they presented their observations like,

1. 25 students reside in the orphanage.

2. Their age group is in between 2 to 10 year old.

3. For every two children, there is one caretaker.

4. These students go to nearby Govt. School.

5. Three students share one dormitory.

6. Breakfast, lunch and dinner are provided by the orphanage. Food is cooked on the orphanage campus. The hygiene and cleanliness are maintained.

7. The students are checked for their health once a month.

8. Students are taken to outings every six months.

9. A television set is made available for entertainment.

10. A small library stands at its place for reading.

11. A small piece of open land acts as a playground where the students usually play around in the presence of their caretakers.

12. Although everything is very meticulously taken care of, the students are not happy. They miss something. When asked about how they are and what they feel, most of them said they miss the love and affection of parents with teary eyes.

One more community engagement the same pack of students happen to visit an Old Age Home named XYZ and the following observations were made.

1. 30 people reside in the old age home, 15 women and 15 men.

2. Their age group is in between 65 to 85 year old.

3. For every three people, there is one caretaker.

4. Two people share one room.

5. Food is cooked at the Old age home according

6. The inhabitants 'health is checked once in a month.

7. They are usually taken to temples and gardens.

8. A television set is made available for entertainment.

9. A small library stands at its place for reading.
10. A small piece of open land acts as a playground where they do yoga exercises in the morning in the presence of their caretakers.

11. Although everything is very meticulously taken care of by the management of the Old Age Home, the people were not happy as they miss something. There is something that hurts them badly and continuously. They have painful and heart touching stories. They cry over their fate. They miss being with their kids and grandchildren. They can't believe their kids backstabbed them when they took utter care of them as kids and raised them.

After these visits, our students were taken aback by the realities of life. They were shattered by listening to the stories of the inhabitants of the old age home. They contacted experts like, Dr Nisha Upadheye who works as a counsellor for people who stay at old age homes, Mr Prashant Kumar who does workshops for old people who stay at Old age Home and Dr Sneha Kishor who works as a Consultant for orphans at NIMHANS.

The students tried to share what they observed, heard and felt about their stakeholders from the Old Age Home and the Orphanage. The following inputs were given to the students.

1. Both the orphans and the old people from the old age homes have a strong craving for being loved and being cared for.

2. They want someone who understands them better.

3. They want someone who can listen to them with genuine compassion and interest.

4. They want someone to tell them that there is somebody who truly wants them in their lives.

5. They want long and strong relationships.

6. They don't like people coming to them as visitors. They don't like to get projected like animals in the zoo.

7. These people carry in their hearts the bad experiences loud and clear which weigh them down. They lose the zeal in living life.

8. One of the best solutions could be connecting the old age home with the orphanage. This particular bondage will catalyse their needs and desires exponentially. This will have a profound and positive implication on the disturbed mindsets of the stakeholders. Scheduling series of get-togethers will serve the purpose.

The human-centred Design Approach aligned the students' mindset on the importance of the needs of the stakeholders. The process made students not only sympathetic but empathetic to the sufferers and understand the real pain behind their smiles. The face to face interviews with the experts validated their concerns for the stakeholders and helped them with myriads of possible solutions to answer the social issue. 
As a part of the implementation, the students have been arranging meetings of the orphans with the old age people for six months. The meetings have helped both the orphans and the old people do a very greater extent on their emotional front.

This is the feedback we received from an old man named Ulhas touches the heart, he said, "I have become a grandfather for twenty kids. I am so happy that god gifted me so many grandchildren. It seems a miracle. Now I don't feel lonely. I earnestly wait for my grandchildren to visit every week. I love them all."(Translated into English from Kannada language.)

This is the feedback we received from a girl of age ten named Sukanya, she said, "I don't know the love of parents as I have never seen them nor have I experienced the love of grandparents. But after I met ajja and ajji in the old age home I feel I have finally got my parents. I carry mithai for both of them. I play with them. I miss them and I like to live with them." (Translated into English from Kannada language.)

\section{The conventional method of teaching leading to the poor performance of the students.}

A group of six students from "C" division namely, Apeksha Kamat, Abhishek Shetty, Nikhil G, Ibza Kittur, Dhananjay $\mathrm{K}$ and Bhoomika $\mathrm{P}$, as a part of their Social innovation Project went to a community for a visit as a part of their initial observation session for the course.

Their first community visit required them to visit the community identified and look for things that looked unusual in society. The student team made their visit to a Government School by name; Siddhavahini Government School located at Sai Nagar, Unkal and stated the following observations made during their visit;

1. 30 to 40 students in each classroom.

2. These students are from the nearby locality

3. The students of age 12 to 13 years were interviewed (Class 7 and 8)

4. There is one teacher for all the subjects.

5. The students were unable to grasp what the teacher taught.

6. The students lacked basic knowledge of the subjects.

7. There were no proper study materials for the students.

8. The students were weak in communicating.

9. They lacked basic communication skills.

10. They were unable to even read and write in English.
11. Students of both the classes were taught in one classroom, hindering the productivity of learning.

12. The parents of the students complained saying there was no homework given to students.

13. There were no extracurricular activities conducted for the students.

14. The student performance was decreasing with each passing day.

The team planned for one more visit to the school and conducted a test for the students to justify their problem statement. Based on the test conducted, the team presented the following observations;

1. The test paper was planned based on their routine syllabi.

2. Citing the statistics, the team stated close to about $75 \%$ of students failed in all the three subjects( English, Science and Maths)

3. The students found it difficult to answer even the simplest of the questions.

After these visit and validating the tests conducted for the students, the team felt that the school students required proper guidance and fun-filled classroom environment to enhance their learning. They contacted experts like, Mrs Nirmala K who works as a principal in a Private school in Hubli, Ms Priscilla Braganza, who works as a Professor at Chetan College, Hubli and Ms Deenaz, who conducts workshops for students who lack basic communication skills.

The students interacted and shared their observations and statistics to the experts. The experts gave the following inputs to the student team;

1. Teachers must adopt Object-oriented teaching.

2. The students should be taught in a creative way to make the learning fun-filled and effective.

3. The students should be given projects to give a boost to their creativity.

4. Workshops can be conducted to keep the students updated.

5. Digital education should be inculcated into their routine syllabus.

6. Computer literature should be made compulsory in Government schools.

7. Students should be taken out of the four walls to make them understand complex things easily.

8. Awareness programmes to be conducted for the students. 
9. Activities should be conducted to enhance their skill set.

10. Training programmes for teachers should be planned to keep them updated.

Human-centred Design Approach helped the student team to step in the shoes of the direct sufferers and understand the reality behind the conventional teaching and learning methods. The inputs given from the experts helped them to think and re-think on what best can be done to find a feasible and effective solution to their social issue.

As a part of the implementation, the student team has conducted a set of workshops using the digital method of teaching, shown them educational videos that helped them in making their basics strong. Post the workshops, the student team conducted one more test to scrutinize the change in the results. The student team was taken by surprise as there was a tremendous improvement in the results. Compared to the pre-workshop test, the students close to about $75 \%$ of students passed in the test and the students were able to read and write basic sentences in English. The following shows the Pre Training and Post Training scores of the students of both Class 7 and 8 for Maths, Science and English. The total number of students who took the test from Class 7 were 30 in number and from Class 8 were 35 in number. We picked up ten students each from class 7 and class 8 randomly for the analysis.

\begin{tabular}{|c|c|c|c|c|c|c|}
\hline Class 7 & $\begin{array}{c}\text { Pre } \\
\text { Trainin } \\
\text { g } \\
\text { Score - } \\
\text { Maths }\end{array}$ & $\begin{array}{c}\text { Post } \\
\text { Trainin } \\
\text { g } \\
\text { Score - } \\
\text { Maths }\end{array}$ & $\begin{array}{c}\text { Pre } \\
\text { Trainin } \\
\text { g } \\
\text { Score - } \\
\text { Scienc } \\
\text { e }\end{array}$ & $\begin{array}{c}\text { Post } \\
\text { Train } \\
\text { ing } \\
\text { Scor } \\
\text { e - } \\
\text { Scien } \\
\text { ce }\end{array}$ & $\begin{array}{c}\text { Pre } \\
\text { Trainin } \\
\text { g } \\
\text { Score - } \\
\text { English }\end{array}$ & $\begin{array}{c}\text { Post } \\
\text { Trainin } \\
\text { g } \\
\text { Score - } \\
\text { English }\end{array}$ \\
\hline $\begin{array}{c}\text { Student } \\
1\end{array}$ & 5 & 15 & 4 & 16 & 2 & 12 \\
\hline $\begin{array}{c}\text { Student } \\
8\end{array}$ & 6 & 18 & 7 & 19 & 4 & 16 \\
\hline $\begin{array}{c}\text { Student } \\
12 \\
\end{array}$ & 4 & 20 & 8 & 22 & 6 & 17 \\
\hline $\begin{array}{c}\text { Student } \\
20\end{array}$ & 3 & 17 & 9 & 20 & 7 & 15 \\
\hline $\begin{array}{c}\text { Student } \\
21\end{array}$ & 1 & 16 & 7 & 21 & 5 & 20 \\
\hline $\begin{array}{c}\text { Student } \\
29\end{array}$ & 11 & 21 & 15 & 24 & 8 & 21 \\
\hline $\begin{array}{c}\text { Student } \\
5\end{array}$ & 21 & 25 & 20 & 23 & 9 & 22 \\
\hline $\begin{array}{c}\text { Student } \\
16\end{array}$ & 14 & 21 & 16 & 21 & 7 & 19 \\
\hline $\begin{array}{c}\text { Student } \\
24\end{array}$ & 16 & 23 & 11 & 22 & 8 & 18 \\
\hline $\begin{array}{c}\text { Student } \\
10\end{array}$ & 2 & 20 & 9 & 20 & 7 & 16 \\
\hline
\end{tabular}

(Table 1: Pre Training and Post Training marks of Class 7)
Following is the Subject wise graphical representation of the improvement seen in the students' performances of Class 7.

\section{Class 7 - Maths - Scores on 25}

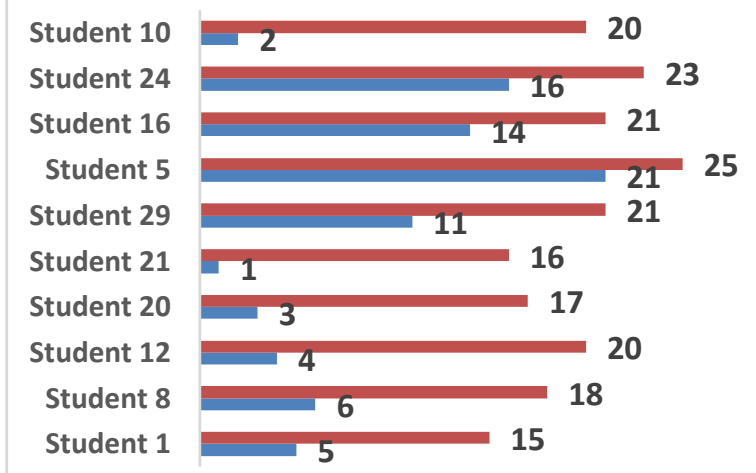

a Post test Score - Maths a Pretest Score - Maths

\section{Class 7 - Science - Scores on 25}

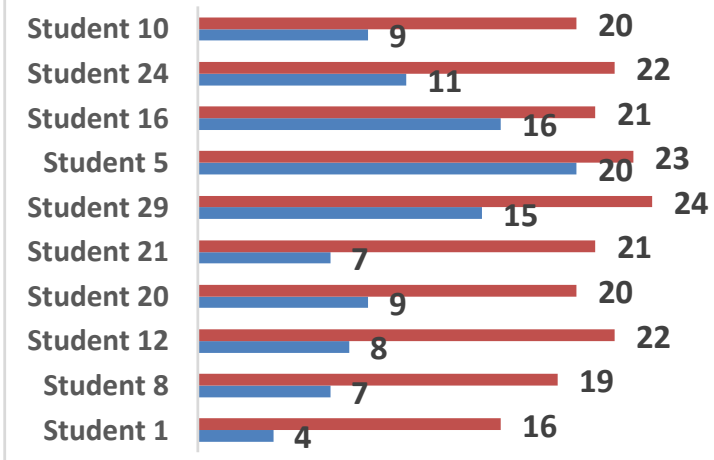

Post test Score - Science Pretest Score - Science

\section{Class 7 - English - Scores on 25}

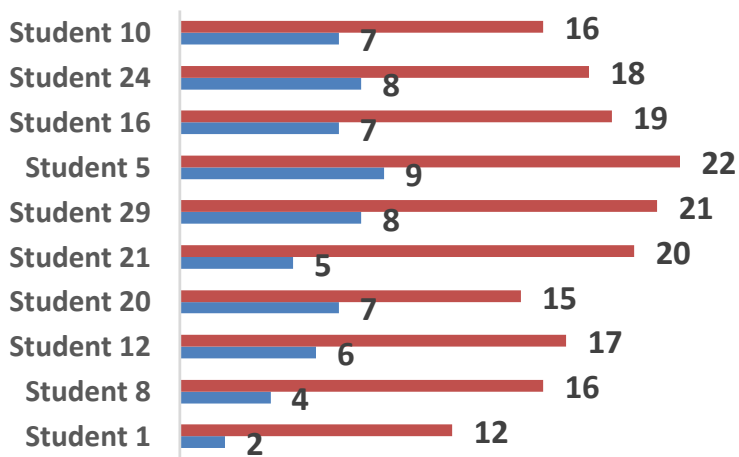

- Post test Score - English $\square$ Pretest Score - English

(Table 2: Graphical Representation Pre Training and Post Training marks of Class 7 


\begin{tabular}{|c|c|c|c|c|c|c|}
\hline Class 8 & $\begin{array}{c}\text { Pre } \\
\text { Trainin } \\
\text { g } \\
\text { Score - } \\
\text { Maths }\end{array}$ & $\begin{array}{c}\text { Post } \\
\text { Trainin } \\
\text { g } \\
\text { Score - } \\
\text { Maths }\end{array}$ & $\begin{array}{l}\text { Pre } \\
\text { Trainin } \\
\text { g } \\
\text { Score - } \\
\text { Scienc } \\
\text { e }\end{array}$ & $\begin{array}{c}\text { Post } \\
\text { Train } \\
\text { ing } \\
\text { Scor } \\
\text { e - } \\
\text { Scien } \\
\text { ce }\end{array}$ & $\begin{array}{c}\text { Pre } \\
\text { Trainin } \\
\mathbf{g} \\
\text { Score - } \\
\text { English }\end{array}$ & $\begin{array}{c}\text { Post } \\
\text { Trainin } \\
\text { g } \\
\text { Score - } \\
\text { English }\end{array}$ \\
\hline $\begin{array}{c}\text { Student } \\
1\end{array}$ & 8 & 18 & 11 & 21 & 10 & 20 \\
\hline $\begin{array}{c}\text { Student } \\
8 \\
\end{array}$ & 9 & 19 & 10 & 22 & 9 & 19 \\
\hline $\begin{array}{c}\text { Student } \\
12 \\
\end{array}$ & 11 & 17 & 13 & 20 & 8 & 21 \\
\hline $\begin{array}{c}\text { Student } \\
20 \\
\end{array}$ & 10 & 21 & 14 & 18 & 12 & 23 \\
\hline $\begin{array}{c}\text { Student } \\
21\end{array}$ & 7 & 19 & 16 & 20 & 13 & 20 \\
\hline $\begin{array}{c}\text { Student } \\
29\end{array}$ & 6 & 20 & 12 & 20 & 14 & 19 \\
\hline $\begin{array}{c}\text { Student } \\
5\end{array}$ & 13 & 20 & 20 & 24 & 19 & 24 \\
\hline $\begin{array}{c}\text { Student } \\
16\end{array}$ & 10 & 21 & 19 & 20 & 14 & 23 \\
\hline $\begin{array}{c}\text { Student } \\
24\end{array}$ & 8 & 20 & 11 & 19 & 9 & 20 \\
\hline $\begin{array}{c}\text { Student } \\
10\end{array}$ & 4 & 22 & 13 & 23 & 10 & 17 \\
\hline
\end{tabular}

(Table 3: Pre Training and Post Training marks of Class 8)

Following is the Subject wise graphical representation of the improvement seen in the students' performances of Class 8.

\section{Class 8 - Maths - Scores on 25}

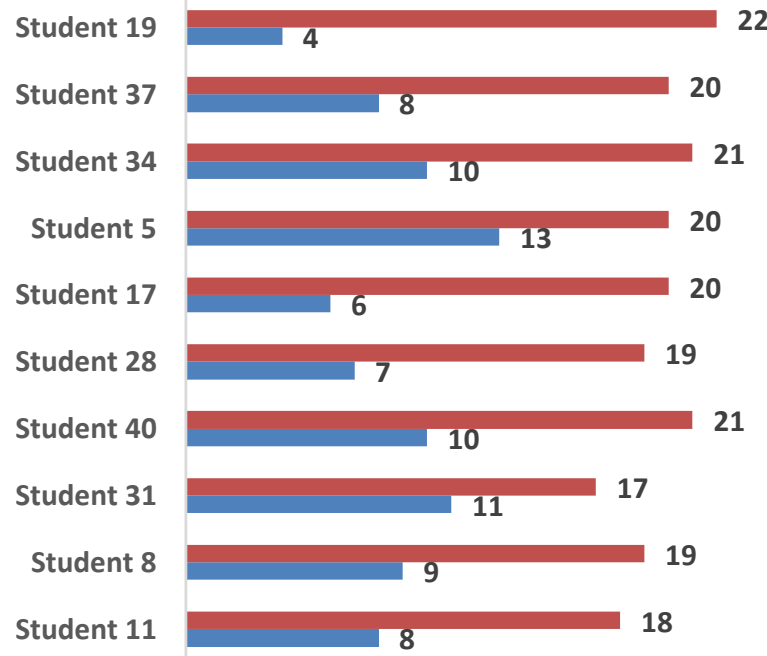

- Post test Score - Maths $\quad$ Pretest Score - Maths

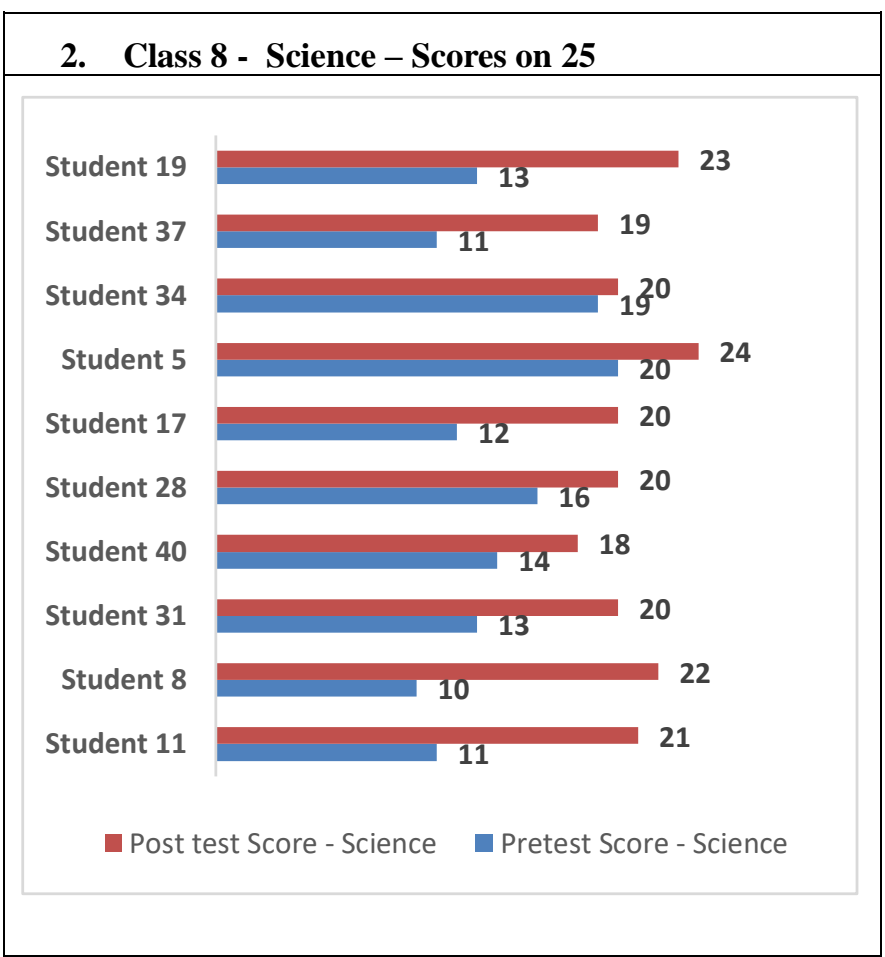

3. Class 8 - English - Scores on 25

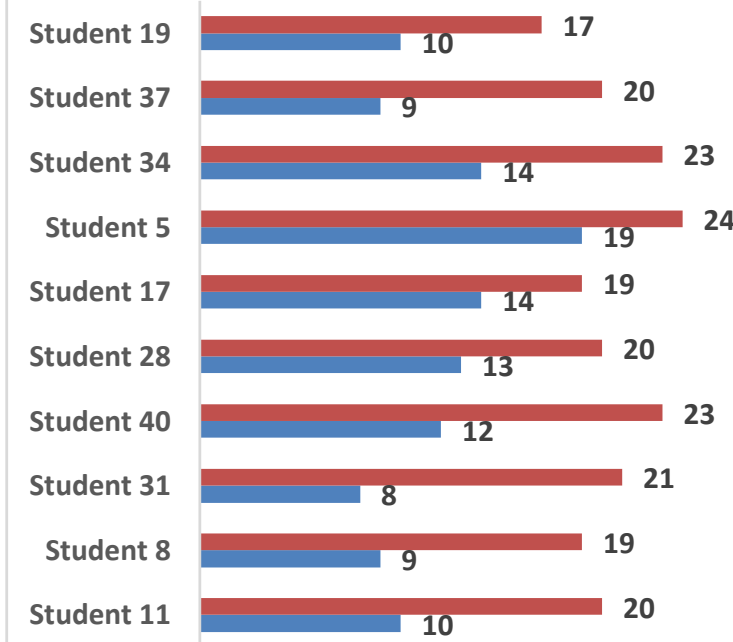

- Post test Score - English a Pretest Score - English

(Table 4: Graphical Representation Pre Training and Post Training marks of Class 7)

\section{Conclusion}

The Human-Centred Design Approach took students one step closer to the stark realities of the lives of the people of different strata. It taught students to keep the needs of the sufferers in the centre and find an answer to the prevailing issues of the society. The social innovation process with the 
HCD approach gave the students an opportunity to become problem solvers for real time social issues in the society.

This experience also changed students' perspective towards society. The students who were pampered by parents all these years got exposed to extremes of life. This experience impacted they perceive the society around them.

Following are the excerpts of the feedbacks we received from our students after their completion of the course.

1. "Initially, I wondered why as an engineer I am supposed to be the part of the course called Social Innovation. It seemed very different. But when I visited the communities, spoke to many people, I was in tears. I am the only child to my parents and that makes me the most pampered one. I got everything even before I could ask my parents.

The pathetic lives of the people left me aghast. The visits got me exposed to many social problems. And I was like, what shall I do immediately to solve their problem. Only then I realized I was a problem solver as an engineer. And also realized the purpose of this course was important for me"

2. "To be factual I was attracted to the course. I thought it will be fun going to communities as they small outings for us. I did not even pay heed to what my facilitator was trying to tell us during the class. My group selected to work on prostitution as a social issue. I did not like the idea. But I thought I wouldn't have to talk with them as I was a non Kannada speaker. So I was relaxed.

My group reached the areas like bus stand and few other places where these women stand for their customers. I listened to the stories of two very young girls probably younger to me too. I was harshly beaten by their ordeals. I realized how comfortable my life has been all these years. I could not resist, I called my parents in the night that day and cried uncontrollably.

It was difficult to convince these girls to change their occupation, we had to take them to a couple of counsellors and psychiatrists and finally they arose from the filth they were working in.

To help these young girls we contacted some small scale industries and with our intervention employed them. These girls are now earning and are happy.

I will always be indebted to this unique course Social Innovation which introduced me to my real self. I will study well as an engineer and after my engineering will work for my people."

3. "I love this course. This course gave me my identity. I understand the society and its people. I can relate to their lives and to their problems far better after this course. I loved these interactive classes. As a part of my project work I got an opportunity to teach Govt. School students. After visiting them I realized how beautiful my life was as a student.
In the span I was connected with these students I helped them in basic mathematics using ABACUS. The children loved it. We as a group of five trained 45 students of Haliyal village. And this will be my best achievement ever. I will miss being part of such activities.

I thank the facilitators of Social Innovation who made this journey wonderful with their continuous support and guidance."

\section{References}

Ideo.org (2015). The Field Guide to the Human-Centered Design: Design Kit. Canada: 